\title{
DE MONJA A CONQUISTADOR, DE MUJER A HOMBRE: LOS VIAJES DE CATALINA DE ERAUSO
}

\author{
FROM NUN TO CONQUEROR, FROM WOMAN \\ TO MAN: THE TRAVELS OF CATALINA DE ERAUSO
}

SORAYA GARCÍA-SÁNCHEZ*

\section{RESUMEN}

En la primera mitad del siglo XVII, la mujer española Catalina de Erauso (1592-1650) fue viajera entre dos continentes, entre condiciones de género. La Catalina novicia cruzó diferentes fronteras y se transformó en Antonio: campesino, vendedor, soldado, alférez, conquistador... Su identidad singular cambió y se pluralizó. Las instituciones religiosas y políticas del momento colonial español admiraron su persona. En sus viajes, disfrazada de hombre, primero por España y después por el Nuevo Mundo, la Monja Alférez imitó el comportamiento varonil y se convirtió en protagonista por sus acciones. Sus ropas y actitudes masculinas le abrieron la puerta a la aventura y al viaje. Con la reflexión de estos acontecimientos, analizaré su vida y su manuscrito, Historia de la Monja Alférez, Catalina de Erauso, escrita por ella misma (1829).

Palabras clave: Cuerpo, escritura de mujeres, identidad, la Monja Alférez, viajes.

\section{ABSTRACT}

During the first half of the seventeenth century, the Spanish woman, Catalina de Erauso (1592-1650) was travelling between two continents, and between distant gender conditions. The religious novice Catalina crossed different frontiers and became Antonio: $a$ peasant, a salesman, a soldier, a conquistador... Her singular identity changed and became more than one personality. The religious and political institutions of the Spanish colonial time admired Catalina's persona. In her journeys, always dressed as a man first in Spain and then in the New World, the Lieutenant Nun imitated masculine behaviour

\footnotetext{
* Departamento de Filología Moderna. Universidad de Las Palmas de Gran Canaria,España. Correo:msgarcia@dfm.ulpgc.es
} 
and became protagonist of her own actions. Catalina's masculine clothes and attitudes unlocked the doors to adventure and travelling. This article will analyse these notions and historical facts in her manuscript, History of the Lieutenant Nun (1829).

Keywords: Body, identity, journeys, the Lieutenant Nun, women's writing.

Recibido: 23.05.12. Aceptado: 08.11.12.

The body is our [...] medium for having a world

MERLEU-PonTY

Poner freno a la mujer es poner límite al mar LOPE DE VEGA

VIAJE E IDENTIDAD DE CATALINA DE ERAUSO: ¿LITERATURA DE VIAJES?

LOS 4 años Catalina ${ }^{1}$ ingresó en el Convento de San Sebastián el
Antiguo, en el norte de España, y tras once años escapó al mundo
exterior, utilizando sus prendas de novicia para convertirse en un joven campesino. Sola, con miedos pero con decisión y valentía, se aventuró al mundo social que observaba ya como si fuese un hombre. Anduvo por distintos pueblos de España, no sólo por el norte sino también en el sur, pasando por San Sebastián, Vitoria, Valladolid, Bilbao, Estella de Navarra, San Sebastián, Puerto de Pasage, San Lúcar y Sevilla. ¿Hubiese sobrevivido, durante este largo recorrido a las agresiones sociales y sexuales si hubiese vestido de mujer? Como fémina sólo habría sido infravalorada y desprestigiada. Fue joven, astuta y sabia al dirigir su propio destino. Desde Sevilla se embarcó hacia las Américas, siendo su tío, sin haberla reconocido, el capitán de la tripulación. Una vez allí trabajó para algunos amos hasta que formó parte de la conquista de América Latina. Es extraordinario todo lo que recorrió. Estuvo en Colombia (Cartagena de Indias, Santa Fe de Bogotá), Panamá, Perú (Paita, Trujillo, Lima, El Cusco, Huamanga), Chile (Concep-

\footnotetext{
${ }^{1}$ A lo largo de este estudio utilizaré el nombre propio de esta increíble mujer, en lugar de su apellido, con el propósito de destacar su persona singular en lugar del apellido común y de descendencia paterna que comparte con el resto de sus hermanos. A su vez, me centraré en la copia editada por Ferrer Historia, y en su edición Cátedra (2002), en lugar de Vida i sucesos (1992) de Vallbona.
} 
ción, Valdivia, Santiago), Argentina (Tucumán, La Plata), Bolivia (La Paz)... Tras confesar su identidad de mujer y su virginidad -momentos en los que se convirtió en la mujer observada-, sólo con el propósito de librarse de la pena de muerte, regresó a España, pasando por Cádiz, Sevilla, Madrid (Consejo de Indias), Pamplona, Barcelona, Lérida, Velpuche y Galera de San Martín. Además llegó a Francia y a Italia cruzando Piamonte, Turín, Tolosa de Francia, Nueva Sicilia, Génova, Roma y Nápoles. Finalmente, retornó a las Américas y se instaló en México, dedicándose al comercio de mercancías entre Veracruz y Ciudad de México. Conoció a personalidades de la historia con mayúsculas como pueden ser el obispo de Huamanga, Fray Agustín de Carvajal, el Papa Urbano VIII (papa de la Iglesia Católica entre 1623 y 1644) en Roma o el rey Felipe IV en España. Su viaje, como su vida y su persona, es realmente sorprendente, considerando su época y su condición de mujer.

Al percibir a Catalina y sus travesías imagino a una viajera cuyo propósito es convertirse en el otro, en el hombre aceptado (viajera romántica), pero sobre todo se representa como "viajer[a] clásic[a] que cultiva la alteridad, la distancia entre su yo y lo que justifica su viaje, la medida de lo <extraño>" (Moureau, 2007: 12). Esta Catalina que no llegamos a conocer realmente, que no expresa sus sentimientos y emociones, debe reprimirse para por fin distinguirse como una protagonista más de sus hazañas y sus encuentros sociales, militares, religiosos y aristocráticos. Catalina sí es una viajera romántica, especialmente astuta al disfrazarse con las prendas que le permitían andar, moverse y hablar libremente. A su vez, Catalina fue una viajera clásica que quiso justificar su viaje a través de sus acciones para satisfacer a la corona y a la Iglesia ${ }^{2}$. Fue astuta también al buscar el reconocimiento político y religioso. Así se justificaría su vida de aventura, se salvaría de la pena de muerte, cobraría una pensión para el resto de sus días y sería nombrada ciudadana romana. Catalina, como otras mujeres viajeras, se muestra inusual, rebelde con las normas sociales del momento. Ese inconformismo

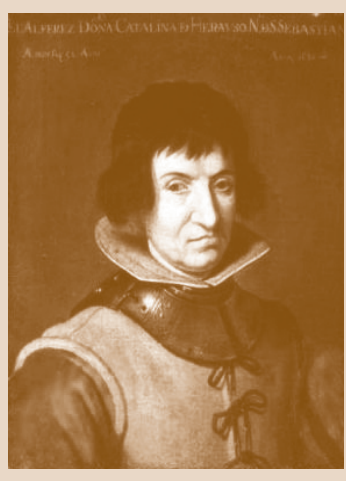

C. de Erauso

\footnotetext{
${ }^{2}$ Con este análisis debo referirme a otras mujeres viajeras del momento ya que Catalina no estaba sola. En su libro Amazons and Military Maids: Women Who Dressed as Men in the Pursuit of Life, Liberty and Happiness, Julie Wheelwright se refiere a mujeres que tomaron la decisión de vestirse de hombres para conseguir sus propósitos, y nombra distintos ejemplos como Valerie Arkell-Smith conocida como Colonel Victor Barker (1926) o Hannah Snell - James Gray (1750). Aunque su estudio se centra sobre todo en mujeres de ascendencia anglosajona, nos sirve de apoyo para reflexionar sobre Catalina. Wheelwright también argumenta como es imposible saber cuántas mujeres eligieron vivir bajo prendas masculinas para desarrollar ocupaciones varoniles. Las que han sido descubiertas sirven como ejemplo de ello pero debemos imaginar que probablemente hubo muchas más que todavía no han sido desveladas (1989: 6).
} 
hace que tome las riendas de su vida y sea doblemente diferente, por un lado, a las mujeres contemporáneas de su momento y, por otro, al hombre viajero (Bassnett, 2002: 226) que nace y se desarrolla según los estereotipos establecidos. Aunque la joven novicia sigue los pasos de éste, el nacimiento, desarrollo e interior de Catalina son los de una mujer. Así la categoría de "conquistador" en honor al reino y a la Iglesia la defiende como cualquier otro hombre de su época.

Según mi conocimiento, nadie ha divulgado el trayecto espacial de los viajes de Catalina y es que sus memorias pueden también enmarcarse dentro del paradigma de literatura de viajes. Historia de la Monja Alférez, además de considerarse un texto primordial en los estudios de mujeres, sigue el prototipo de la literatura de viajes, es decir, registra lugares, situaciones y personas que Catalina encuentra en su camino. La literatura de viajes es:

[un] subgénero literario constituido por aquellos escritos (crónicas, diarios de a bordo, cartas, informes, etc.) cuyo objetivo es, esencialmente, la narración de una experiencia vivida. Al viajero -conquistador, misionero, marino o científico- que ha descubierto nuevas tierras y culturas, que ha conocido otros países y pueblos, no le basta con aportar pruebas materiales de tales hechos, sino que se ve en la necesidad de contarlos y de dejar constancia escrita de ello (Oliver et al., 2007: 9).

La autobiografía presuntuosa de Catalina no puede quedar excluida de esta definición. Como viajera y conquistadora Catalina refleja en su texto sus descubrimientos que, al mismo tiempo, van a servir como pruebas para testificar su vida aventurera y para que quede constancia en la historia de la mujer. Quizás su narrativa no manifiesta un viaje de comodidad y bienestar sino un viaje de necesidad, exploración y, sobre todo, de conquista y descubrimiento ya que no es hasta el siglo XIX que se viaja por placer (Moureau, 2007: 11). No sólo batalla Catalina las Américas sino también las miradas y valores de la sociedad española que termina aceptando y glorificando su persona varonil.

Lo mismo sucede con su descubrimiento personal que manifiesta Catalina en sus trayectos. El viaje de Catalina de Erauso implica un viaje personal. No sólo va descubriendo lugares y personas que jamás había imaginado, sino lo que es capaz de hacer por sí misma. Por otro lado, a pesar de utilizar los medios de transporte de su época como son el barco o las incansables mulas y caballos, Catalina también anduvo innumerables kilómetros a pie. En sus memorias, la protagonista refleja la agitación del viaje que la llevó en varios momentos casi a la muerte: 
Comencé a caminar por toda la costa del mar, pasando grandes trabajos y falta de agua, que no hallé en todo aquello de por allí; tópeme en el camino con otros dos soldados de mal andar, seguimos los tres el camino, determinados a morir antes que dejarnos prender. Llevábamos nuestros caballos, armas blancas y de fuego, y la alta providencia de Dios (De Erauso, 2002: 120).

La literatura de viajes abarca, por un lado, narraciones personales con motivos conscientes, conflictivos y con una resolución de personalidad y, por otro, narraciones impersonales con una estructura lineal (Blanton, 2002: 3). Historia de la Monja Alférez presenta combinaciones de ambas formas ya que primero sigue una estructura lineal, narrando su vida desde sus orígenes en España y, seguidamente, sus aventuras en el Nuevo Mundo. Sin embargo, al mismo tiempo, la narración de su viaje se concentra en exaltar acciones heroicas. Aunque sus memorias se relatan según la estructura lineal, la protagonista muestra conscientemente su motivación para que sus hazañas se reconozcan. Incluso, su personalidad, muy violenta y a la constante defensiva, queda definitivamente resuelta en sus desafiantes encuentros con cualquiera que deshonre su persona. Un ejemplo de ello se aprecia en el último episodio de sus memorias. Dos mujeres se burlan de Catalina y ésta reivindica su conflicto por mantener su posición, incluso delante de estas féminas: "En Nápoles, un día, paseándome en el muelle, reparé en las risadas de dos damiselas que parlaban con dos mozos, y me miraban. Y mirándolas, me dijo una -Señora Catalina, ¿dónde es el camino?- Respondí: -Señoras p... a darles a ustedes cien pescozadas, y cien cuchilladas a quien las quiera defender-. Callaron y se fueron de allí” (De Erauso, 2002: 175). Con estas palabras es imposible no imaginar la expectación que provocaba la figura de la Monja Alférez, después de su confesión y del consentimiento por parte del rey y del Papa a continuar vestida con ropas de hombre. Aún todavía cuando lo escribo me parece que sigue siendo una historia de ficción. En todo caso, la literatura de viajes se relaciona con la parodia y la falsificación y en alguna ocasión puede parecer que Catalina emplea estos términos. A su vez, la ausencia del texto original ha provocado que se dude de la autoría de Catalina ${ }^{3}$. Como viajera solitaria que desconfía de muchos, Catalina quizás manifestó sus acciones con un relato exagerado, ficticio, que en ocasiones parece más una falsa que una realidad.

\footnotetext{
${ }^{3}$ Véase el estudio de Rima de Vallbona en el que se menciona, por ejemplo, a Diego Barros Arana como uno de los críticos que cuestiona la autoría de Catalina en Historia en 1872: "a la cual no se pueden atribuir ni práctica de escribir, ni gusto literario" (Vallbona, 1992: 6).
} 
Luisa Valenzuela argumentó que el viaje se corresponde con el cuerpo al estar en constante movimiento (1993: 4-6). Movimiento a Catalina no le faltó y este proceso establece el descubrimiento de su persona al pasar del convento a la calle y en absoluta soledad, sin confiar en mucha gente. Además su viaje, desde que llega a América, es un viaje de encuentro, no sólo del nuevo continente sino de sí misma. Atraviesa diferentes lugares con una gran variedad de dificultades pero consigue seguir su camino. En la protagonista, lo más importante de su escritura es hacer constar los espacios y, sobre todo, las personas que se encuentra, por la sencilla razón de verificar su narración y conseguir un reconocimiento histórico. Pero ésta que describe es su identidad social, con la que se desenvuelve libremente para que la conozca la sociedad aunque bajo el nombre de Antonio. Al esconder su cuerpo de mujer, el interior de Catalina queda para nuestra imaginación, como así lo han interpretado Gloria Durán y Juanita Gallardo en sus novelas dedicadas a Catalina: Catalina, mi padre (2004) y Confesiones de la Monja Alférez. La verdadera historia de Catalina de Erauso (2005), respectivamente. Durán muestra a una Catalina que hace la función de padre de Sor Juana Inés de la Cruz. A través del punto de vista de Sor Juana y de una carta que escribe Catalina para su hija no biológica conocemos el interior de Catalina que llega a manifestar sus secretos más guardados a través de la confesión epistolar. Catalina además de conquistador, también se describe como padre, como mujer que desvela su interior desconocido. Al mismo tiempo, la obra de Gallardo muestra en este caso a través de la tercera persona a Catalina en el momento de la confesión al obispo de Huamanga. Toda la trama se centra en la escritura de sus memorias y en el encierro inicialmente en el hogar del obispo y después en el convento. Tras volver a llevar las prendas de novicia, Catalina se muestra cautelosa para escribir un texto que convenza al religioso, la salve y le permita volver a su libertad en el mundo exterior. Gallardo refleja la conciencia de Catalina cuya emancipación depende de su texto, de narrar lo que querían leer.

Con el viaje se hace referencia al movimiento y a la expresión de distancia que emplea Catalina en su autobiografía: las leguas. Una legua comprende un recorrido de entre cuatro y seis kilómetros y se calcula en función de la distancia que una persona llega a andar en una hora. En el caso de Catalina hay que considerar que cuando el camino es montañoso y dificultoso se hace el tramo más complicado y más largo. Por otro lado, si la "calzada" es transitable, el camino es más fácil de acceder y de recorrer. Todavía en algunos países como México en sus zonas rurales, se sigue utilizando la legua como medida que se puede andar en una hora. Así que la legua también 
refleja no sólo el tamaño del trayecto sino el esfuerzo físico del caminante que Catalina describe bajo el género masculino, el género en el que vivió sus hazañas: "Corridas como cuatro leguas largas desde aquí, llegué a Plata, bien fatigado y cansado" (De Erauso, 2002: 139-40). En muchos otros ejemplos refleja la Monja Alférez lo agotador del viaje: "Comencé a caminar por toda la costa del mar, pasando grandes trabajos y falta de agua, que no hallé en todo aquello de por allî" (De Erauso, 2002: 120). Si la legua además se compara con las medidas contemporáneas del kilómetro o la milla, la primera no conoce otra forma de llegar que no sea a través del físico humano o animal, con lo que la narrativa de Catalina acentúa su esfuerzo corporal.

Casey Blanton argumenta que la literatura de viajes intenta contar una verdad que paradójicamente podría no ser dicha (2002: 2). La historia de Catalina parece una fantasía, y aunque corta, refleja su viaje espacial, su viaje temporal y su viaje personal y de género en un mundo dominado por los hombres. Si volviese a organizar su viaje según los espacios recorridos, su aventura se podría ver como una de conquista, de descubrimiento, comparable con otras personalidades de la historia como Cristóbal Colón. Catalina comparte con el descubridor de América el egotismo de su voz. Ambos protagonizan y enfatizan sus voces en la narración de sus textos. Con el viaje, Catalina se convierte conscientemente en alguien diferente que quiere que sus hazañas se consideren auténticas. Como describe Bassnett: [M] any of the works by women travelers are self-conscious fictions, and the persona who emerges from the pages is as much a character as a woman in a novel" (2002: 234) ${ }^{4}$. Catalina es una protagonista de ficción en su propio texto de viajes. Narra conscientemente los acontecimientos que la sociedad quiere escuchar con la única intención de ser y permanecer en su estatus de mujer-hombre, femenina-masculino, monja-alférez.

Las memorias de la Monja Alférez siguen también el patrón de la literatura de viajes que normalmente contiene tres fases en su composición: la salida, la aventura y el regreso. En Historia, Catalina relata primero su partida, y aquí incluye su escapada del convento, sus primeras experiencias bajo el disfraz de hombre y a su familia con una breve descripción. Antes de su partida, la heroína consigue hablar principalmente de sus padres y, al mismo tiempo, se incluyen en el texto para darlos a conocer y llegar a despedirse de ellos, aunque siempre bajo su disfraz: "Nací yo, doña Catalina de

\footnotetext{
4 "Muchos de los trabajos de mujeres viajeras son ficciones conscientes, y la persona que emerge de las páginas es tanto un personaje como una mujer en una novela”. Ésta y las traducciones posteriores del inglés al español son mías.
} 
Erauso, en la villa de San Sebastián, de Guipúzcoa, en el año 1583, hija del capitán don Miguel de Erauso y de doña María Pérez de Galarraga y Arce, naturales y vecinos de dicha villa" (De Erauso, 2002: 93). La segunda etapa de la literatura de viajes es la aventura y ésta se centra especialmente en el largo recorrido hasta y por las Américas, aunque no sin dejar de incluir sus más arriesgados eventos por San Sebastián, Vitoria, Valladolid, Bilbao, Estella de Navarra, San Lúcar y Sevilla, ya disfrazada de hombre. Esta segunda fase de su narración incluye estos espacios españoles en los que observa y personifica su papel varonil. Asimismo, viaja por otras ciudades de Colombia, Perú, Chile, Argentina y Bolivia. Un ejemplo significativo de esta continua aventura surge cuando Catalina decide quedarse en el Nuevo Mundo en lugar de regresar a España con su tío, a quien le roba quinientos pesos para subsistir en su viaje solitario. Lo detalla en descripciones precisas de sus tácticas y del tiempo: "A las diez de la noche, cuando él estaba durmiendo, salí y dije a los guardas que me enviaba el capitán a un negocio en tierra. Dejáronme llanamente pasar como me conocían. Salté a tierra y nunca me vieron más" (De Erauso, 2002: 100).

Desde el comienzo y hasta el final de su trayectoria narrativa, donde Catalina se sitúa en Roma y finalmente en Nápoles, la estructura es una compleja variación de episodios en diferentes países del viejo y nuevo continentes, donde sigue predominando la segunda fase de los textos tradicionales de viaje: la aventura. Sin embargo, después de su confesión, Catalina retorna a España y este trayecto correspondería con la tercera fase de los textos de viaje: el regreso. En el caso de Catalina, su vuelta a España no significa que haya concluido con su vida de viajes y aventuras sino que tiene un propósito: el reconocimiento político por parte del rey de España, y religioso por parte del Papa en Italia, donde también le dieron la valoración de ciudadano romano (De Erauso, 2002: 174). En la literatura de viajes tradicional, todos estos acontecimientos formarían parte del regreso, pero en el caso de Catalina (aunque retorne a su tierra natal), pertenecen a la fase constante y predominante de su vida: la aventura, la aventura de un viaje, la aventura de su vida. Se ejemplifica así en el último episodio, donde además de seguir luchando por su posición social, expresa la continuación de su viaje con fechas exactas que hacen su manuscrito más creíble: "Pasado mes y medio que estuve en Roma, me partí de allí para Nápoles, el día 5 de julio de 1626. Embarcamos en Ripa. En Nápoles, un día, paseándome en el muelle" (De Erauso, 2002: 175).

En el viaje de Catalina impera su constante aventura. Después de Italia pasó por España y volvió al Nuevo Mundo para permanecer allí el resto 
de sus días. Su viaje implica entonces dos regresos, primero a España, y después a México donde reside y fallece en 1650 como se narra en la tercera relación": "El año 1650, yendo por el camino nuevo con carga fletada a la Vera Cruz, adoleció en Cuitlaxtla del mal de la muerte, y falleció con una muerte ejemplar y con general dolor de todos los circunstantes" (De Erauso, 2002: 197). Tanto su aventura como la conquista de las Américas fueron agentes de gran importancia en su liberación y supervivencia que, a su vez, se corresponden con el viaje y el movimiento que ya destacó Luisa Valenzuela en relación al cuerpo. Catalina escribió sin renunciar al disfraz de hombre conquistador, figura reconocida y valorada por la sociedad. Además, el motivo principal de su viaje y de su escritura individual busca la absolución y el reconocimiento honorable por parte del monarca y de la Iglesia. Reflejarlo en papel salvará su vida sin condenarla a la muerte. Su viaje decidido hace que la protagonista siga en movimiento, sin un destino estático ni permanente. Sólo los caminos que atraviesa Catalina de Erauso formarán su hogar. Tanto el viaje como el espacio y el tiempo se convierten en factores primordiales de la liberación de la Monja Alférez. Lo desconocido que ofrecían los nuevos espacios, el viaje y la conquista hizo que esta increíble mujer viviera su emancipación en el siglo XVII. Aunque también la imagino en constante lucha por mantener otros secretos.

Para concluir, con este primer análisis resumo y comparo brevemente la estructura de un texto tradicional de la literatura de viajes con las memorias de Catalina para resaltar cómo en todas las etapas de su viaje predomina la aventura, que seguramente permanecería en su vida para el resto de sus días.

Estructura de la literatura de viajes

1. Narrativa tradicional:

Salida

Aventura

Regreso

2. Narrativa de Historia de la Monja Alférez:

Salida-Aventura = escapa del convento en España, se ve y comporta como hombre y hace referencias a la familia.

${ }^{5}$ Una relación es una forma narrativa de los hechos de un viaje que solían emplear los cronistas de la época colonial. Las tres relaciones sobre Catalina se escribieron después de su muerte. 
Aventura = España y las Américas.

Regreso-Aventura = España e Italia para ser reconocida como hombre.

Salida-Regreso-Aventura = Vuelve al Nuevo Mundo para vivir allí el resto de sus días.

\section{RELIGIÓN, ESCRITURA, VIAJE Y GÉNERO “SÚPER MASCULINO”}

El viaje y la vida de Catalina quedaron justificados por sus acciones en la conquista y por su devoción religiosa. Su individualismo y variación de género de mujer a hombre cuando escapa del convento, de hombre a mujer cuando confiesa que también es virgen, y de mujer a hombre cuando regresa a España para pedir perdón y reconocimiento hace que sea relevante analizar su identidad unida a la noción de "gender performativity" dith Butler y, a su vez, a la utilidad de la religión católica.

Si el género se construye social y culturalmente, la percepción de "gender performativity" implica la actuación y representación del mismo. En este sentido, la teoría de Butler se aplica a Catalina. Su interpretación y actuación, después de haber copiado el comportamiento masculino, se convierte en éxito que "libera" su posición en la sociedad. El concepto de Butler podría aplicarse a Catalina desde su ingreso al convento. Como hija menor de la familia Erauso-Gallarraga y Arce y, como mujer, su feminidad se limita a la posición de convertirse en monja. Su sexo y género femenino condicionan su vida y su destino. Sin embargo, su postura al escapar del convento y convertirse en la figura que acepta la sociedad, el rey y el Papa es un claro ejemplo de construcción de género, de actuación y de sutileza.

Se hace necesario tener presente las marcadas diferencias de género entre el siglo XVII y nuestra época actual, en cuyo caso resaltan mayores contrastes. Marjorie Garber ejemplifica como durante siglos tanto los niños como las niñas estaban vestidos con prendas similares que no hacían notable la distinción genérica (1993: 1). Así era difícil diferenciar a las niñas de los niños. En algunos casos no sólo las prendas imposibilitan la certeza del género sino sus peinados similares. Tanto el niño como la niña llevaban el pelo corto o bien recogido haciendo la diferenciación genérica un juego de adivinanza e interpretación. Estas cuestiones físicas forman parte del géne-

\footnotetext{
${ }^{6} \mathrm{La}$ "construcción del género" se refiere a los actos que lleva a cabo una persona según sea su género masculino o femenino. Por ello, el género no es puro en su esencia sino se construye a través de la identidad que se alega ser (Butler, 1994: 25).
} 
ro que impone la sociedad y que Catalina utilizó a su favor siendo aceptada y valorada por la Iglesia Católica.

En este sentido, y aunque es un término moderno, travestismo ${ }^{7}$ se insinúa como característica que define a Catalina. Según Garber: "crossdressing $[\ldots]$ offers a challenge to easy notions of binarity, putting into question the categories of 'female' and 'male', whether they are considered essential or constructed, biological or cultural" (1993: 10) ${ }^{8}$. El travestismo va más allá de lo binario y reta entonces a otras opciones genéricas. Aunque la concepción de travestismo no constaba en el siglo XVII, esta referencia a lo esencial o construido es relevante en Catalina y en el panorama de la religión católica que no sólo separa al hombre de la mujer, es decir, al género masculino del femenino, sino que separa a las féminas entre sí mismas con restricciones binarias, siendo una mujer aceptada, buena, pasiva, virgen, y la otra, rechazada, mala, activa y prostituta. Catalina rompe, a través del travestismo y de su actuación religiosa, con el binarismo para unir valores opuestos. Es novicia y conquistador, novicia-monja y finalmente comerciante. Según Víctor Rocha, con el travestismo, Catalina experimenta "el ocultamiento y negación de los signos [de] la feminidad con el propósito de transformarse en soldado de espada y cruz" (2003: 1). Todas sus hazañas se reflejan en su honra a la conquista y su devoción religiosa. Como religiosa, Catalina fue un miembro valorado por la sociedad, pero ¿cumple Catalina con los mandamientos de la Iglesia, que se resumen en amarás a Dios sobre todas las cosas y a tu prójimo como a ti mismo? Los incumple pero los justifica en nombre de la patria y de la Iglesia.

Al leer su manuscrito se aprecia cómo Catalina ama a Dios sobre todas las cosas y también al prójimo, excepto en los casos en los que su persona y condición se ven desafiadas. En esos momentos exterioriza su carácter "supermasculino" para defender a toda costa su condición social. Los mandamientos cuatro (Honrarás a tu padre y a tu madre) y seis (No cometerás adulterio) sólo podemos imaginarlos ya que no sabemos a día de hoy si los padres de Catalina se sintieron deshonrados por sus acciones o si, por otro lado, las aventuras de su hija los llenaban de orgullo. Sin embargo, es difícil pensar en lo segundo teniendo presente la vida del siglo XVII y con-

\footnotetext{
${ }^{7}$ Travestismo (cross-dressing) es el término que procede del latín "trans” de cruzar o sobrepasar y "vestere” de vestir que acuñó el doctor sociólogo y sexólogo alemán Magnus Hirschfeld en 1910 con su obra Transvestites: The Erotic Drive to Cross-Dress.

8 "[T] ravestismo ofrece un reto a nociones binarias simples, cuestionando las categorías de lo ‘femenino' y lo 'masculino', sean consideradas esenciales o construidas, biológicas o culturales”.
} 
siderando cómo la rebeldía de Catalina mostraba desacato e irrespeto hacia sus padres. Como hija menor debía de haber permanecido en el convento y ser monja, completando ese otro valor en la familia. Al mismo tiempo, si Catalina se expresó o no sexualmente en el caso de que se haya o no comprometido en secreto, pues tampoco lo sabremos a ciencia cierta, ya que los documentos que engloban su vida son más bien escasos y ambiguos, "pero no tiene escrúpulos en enamorar a más de una mujer hasta prometerle matrimonio" (Vallbona, 1992: 10), ya sea para preservar su supermasculinidad o por satisfacción propia. Es incuestionable que iba con cierta verdad por delante y que confesó todo lo que debía en su momento, cuando lo necesitó para librarse de la pena de muerte por asesinar al nuevo Cid de Cuzco, que describe como "un hombre moreno, velloso, muy alto, que con la presencia espantaba” (De Erauso, 2002: 152). Matar si mató como soldado, conquistador, pero no lo hizo en vano sino bajo las órdenes del reino de España y bajo su condición de religiosa incondicional cuyas doctrinas compartía para participar en la formación y transformación de los nuevos conquistados "salvajes" en católicos cristianos. Especialmente, sus acciones se formalizaron bajo el mandato general "amarás a Dios sobre todas las cosas" y es bajo estas circunstancias y bajo la condición de virgen como se salva y como consigue la admiración de la Iglesia.

Tanto la vida religiosa como el convento le dieron cierta autonomía a Catalina cuya declaración al obispo don fray Agustín de Carvajal de que es mujer y además virgen la salva de su fin. Bárbara Mujica apunta como es a través de la religión como las mujeres consiguen sus más altas posiciones en la sociedad de la época: "Perhaps the area in which women exercised the greatest leadership was religious life" (2004: xxxi) ${ }^{9}$. El convento es para Catalina el comienzo de su formación y de su atrevimiento hacia la aventura y, al mismo tiempo, el convento se convierte en el lugar de salvación, refugio y espera que le sirve de impulso a su definitiva vida como la Monja Alférez, como Catalina-Antonio de Erauso. Es relevante prestar atención al momento de la confesión en el espacio religioso como el que separa los dos géneros -el exterior y el interior, el visible y el escondido, el masculino y el femenino- resaltando ahora el cuerpo de mujer y su condición virtuosa: "A la tarde, como a las cuatro, entraron dos matronas y me miraron y se satisficieron, y declararon después ante el obispo con juramento, haberme visto y reconocido cuanto fue menester para certificarse y haberme hallado virgen intacta, como el día en que nací (De Erauso, 2002: 161)”.

\footnotetext{
9 "Quizás el espacio que concedió mayor liderazgo a las mujeres fue la vida religiosa".
} 
La confesión de Catalina determina su propia salvación. Un poderoso representante de la Iglesia podrá juzgar y valorar sus acciones ante sus creencias. Una vez que se descubre, la Monja Alférez relata sus experiencias más relevantes en un texto cuya narración se expresa en forma de confesión $^{10}$. La confesión implica referencias religiosas. Según la Real Academia Española, confesión es un sacramento de penitencia, un credo religioso y, a su vez, un relato que alguien hace sobre su propia vida para explicarla a los demás. Tanto el espacio religioso como el oyente de sus acciones, como la forma de su historia culminan este momento esencial, y acaso estratégico, de la vida de Catalina.

Confesiones de la Monja Alférez. La verdadera historia de Catalina de Erauso (2005) de Juanita Gallardo es una de las más recientes novelas inspiradas en esta mujer histórica que refleja los valores religiosos del acto de confesar. Gallardo centra su texto en el momento de la confesión, primero oral, y luego escrita, por orden del obispo: "Quiero que escriba su vida empezando por el día en que llegó a este mundo. De aquí no sale por un buen tiempo, así que escriba" (2005: 12). En esta novela histórica Catalina se manifiesta rodeada del entorno religioso ya que reflexiona y se preocupa por poner en papel una confesión exacta, aceptada, justificada que llegue a valorarla y a salvarla de la pena de muerte. A Catalina la vemos desde la tercera persona que la describe con adjetivos masculinos: "Bastará cumplir con lo que el obispo le ordena para volverse inocente, redimido, puro" (2005: 16).

Esta confesión en forma de testimonio gusta al obispo que protagoniza a don fray Agustín de Carvajal, representante de la Iglesia en el Cuzco durante su arresto. Gracias a esta figura jerárquica, Catalina se salva de la pena de muerte, regresa a España vestida de monja y, finalmente, continúa vistiendo como hombre de la época, después de haberse pasado varios años encerrada en el convento mientras esperaba la notificación positiva de Es-

\footnotetext{
${ }^{10}$ Aunque confesión no es lo mismo que testimonio, hay cierta correspondencia entre ambas expresiones a la hora de estudiar el texto de Catalina. El segundo se refiere más a una prueba que justifique una verdad. John Beverley (2004) asegura que testimonio lleva la connotación de decir la verdad ya sea en un sentido legal o religioso. Testimonio implica entonces un diálogo entre el narrador y el lector, y no llega a ser objetivo sino subjetivo. El narrador habla de historia, de sus eventos. Refleja su vida a través de la forma literaria y de la primera persona. Su historia se singulariza al describirse. En el caso de Catalina, su narración es en primera persona, subjetiva y exagerada. Habla de sí misma y de sus experiencias y circunstancias aquí y allí, en todos los lugares relevantes y con las personalidades importantes que se encuentra en el camino. Esta literatura testimonial también se desarrolla en la literatura de viajes, mientras que la confesión implica un acto de conciencia, rendimiento y honestidad, y finalmente, liberación.
} 
paña que confirmara que Catalina era sólo novicia y no llegó a jurar sus votos. Catalina no podía ser condenada por sus aventuras varoniles porque había sido novicia durante más de diez años, y la categoría religiosa le daba poder. Del mismo modo, tampoco podía sentenciarse como mujer ya que fue un soldado ejemplar. Para Catalina, la creación de sus memorias hace que relate sus hazañas para que el honor reemplace a la muerte como refleja Gallardo en su obra, en la que prefiere utilizar la narración en tercera persona y el género masculino para referirse a la Monja Alférez:

Quisiera entregar un relato maravilloso y heroico de sus hazañas para dar pruebas al mundo -o, al menos, al obispo de Huamanga- de su valentía, pues, si el hombre es la medida de todas las cosas, él, que tantas hazañas ha protagonizado, merece más que el común de sus congéneres $y$, en consecuencia, en vez de enviarlo a la muerte, la sociedad le debe un puesto de honor (2005: 16).

Aunque la forma de escritura de Catalina no muestra el interior que se identifica con varios textos de la literatura contemporánea de mujeres ${ }^{11}$, sí es cierto que hablamos de épocas históricas muy diferentes y de condiciones y circunstancias para la mujer considerablemente contradictorias. El texto corto de Catalina refleja su viaje espacial, su viaje temporal, y su fugaz viaje personal y de género en un mundo dominado por los hombres y ¿ cómo, si no, pudo haberse considerado su texto, sino bajo su disfraz masculino? Predomina su perseverancia por mostrarse como hombre. Hombre que se comporta y lucha como tal para defender al reino de España. ¿Cómo iban a negarle reconocimiento si logró igualarse al canon establecido? En el siglo XVII la escritura de mujeres ni siquiera se sugería o se pensaba como opción para los intelectuales, en todo caso, se ridiculizaba todo pensamiento que apoyara esta práctica. Pero Catalina puso en marcha su contribución como mujer viajera audaz, heroica y escritora, narrando sus aventuras en primera persona.

La forma narrativa que emplea Catalina es una escueta autobiografía que en ocasiones parece más ficción, una novela épica por sus exageradas acciones heroicas. En la edición de Historia de la Monja Alférez, Catalina de Erauso, escrita por ella misma de Ángel Esteban se describen los cuatro estilos de narración de la época de Catalina:

\footnotetext{
${ }^{11}$ Rita Felski pone como ejemplo de narración feminista las obras de Margaret Atwood, Surfacing o de Joan Barfoot, Gaining Ground. En ambos casos, las escritoras manifiestan la narrativa interior de descubrimiento personal y de viaje espiritual (1989: 13).
} 
[L] os libros de caballerías, la novela manierista, la novela barroca y un grupo más amplio con "narraciones de características más modernas que mezclan en dosis variables episodios verdaderos y ficticios con finalidad de construir ejemplos intencionalmente dirigidos a la comunidad o a los Príncipes, al modo de muchos relatos clásicos, aparentes narraciones autobiográficas o libros de viajes imaginarios" ${ }^{\prime 2}$.

Esteban argumenta cómo la obra de Catalina pertenece a este último subgénero y se describe como "una narración autobiográfica combinada con materiales propios de libros de viajes de la época, y con un estilo picaresco, también muy común en el Siglo de Oro hispánico" (De Erauso, 2002: 20). Esta combinación de estilos es característica también de la literatura feminista que experimenta con sus textos.

Al mismo tiempo la autobiografía de Catalina también se incluye dentro de los parámetros del testimonio, como estilo empleado para documentar lo vivido. Esta forma de narración se sugiere en ejemplos de literatura de mujeres ya que el testimonio siempre cuestiona (de forma directa e indirecta) distintos aspectos que el escritor descubre al lector. Tiene un objetivo de crítica político, ético, social, religioso... que la mujer escritora evalúa en su narración. El testimonio implica decir la verdad sobre las experiencias del narrador en un sentido legal (o religioso), es decir que el texto forma parte de la historia, como manifestó John Beverley (2004: 3-4).

El texto de Catalina formaría entonces también parte del argumento testimonial ya que los eventos que relata se relacionan con el momento histórico, con el viaje y la vida de la narradora, haciendo que su obra sea también parte de la historia con mayúsculas, como muestra en el episodio $\mathrm{V}$ de Historia. Catalina se incluye en el texto que compara, documenta y describe la estructura política, social y religiosa de la ciudad de Lima:

Lima, cabeza del opulento reino del Perú, que comprende ciento y dos ciudades de Españoles, sin muchas villas, veintiocho obispados y arzobispados, ciento treinta y seis corregidores, las audiencias reales de Valladolid, Granada, Charcas, Quito, Chile y La Paz. Tiene arzobispo, iglesia catedral parecida a la de Sevilla, aunque no tan grande, con cinco dignidades, diez canónigos, seis raciones enteras y seis medias, cuatro curas, siete parroquias, doce conventos de frailes y de monjas, ocho hospitales, una ermita (inquisición y otra en Cartagena), universidad. Tiene

${ }^{12}$ En estas líneas se hace referencia a la obra de Fernando Aínsa, Identidad cultural de Iberoamérica en su narrativa, 1986, p. 120 (Historia, 2002: 20). 
virrey y Audiencia real que gobierna el resto de Perú, y otras grandiosidades (De Erauso, 2002: 108).

\section{CONCLUSIONES}

Escribir implica ver, escuchar, saber, leer, reflexionar, narrar, describir... En el caso de Catalina, su apellido noble le dio cultura y educación. La escapada al nuevo continente le concedió libertad y más conocimiento, más tolerancia con la que vivir, trabajar y convencer a los otros de su supervivencia. José Luis de la Fuente Bastardo hace especial referencia a la mujer en Hispanoamérica y argumenta que "ha pasado de personaje a persona, de tinta en un trozo de papel a escritora reconocida; primero, luchadora en solitario y, después, reivindicadora junto al hombre de los desastres que han sacudido al continente" (2000: 191). Catalina cambió la acción de ser observadora a ser observada. No acompañó a ningún hombre en particular, como así lo hiciera Inés Suárez con Valdivia en la conquista de Chile, sino que se transformó en uno de ellos pero siempre en solitario. Sola persiguió el canon establecido para conquistar Chile, Perú, Bolivia, Argentina,... Su temperamento, su decisión y su valentía iniciaron a esta mujer en un mundo por descubrir, muy diferente al que dejó atrás en España, sin reglas estipuladas que debía cumplir por su condición y estatus de mujer. Debía llevarlo a cabo sin confiar en mucha gente. En las Américas las reglas que desempeñó Catalina eran las de hombre que tenía derechos y obligaciones. Catalina luchó por el reino de España y conquistó el derecho de seguir libre bajo sus prendas de alférez y de conseguir una contribución económica por parte del rey: "Víneme a Madrid, presentéme ante S.M. suplicándole me premiase mis servicios, que expresé en un memorial que puse en su real mano... me señaló ochocientos escudos de renta por mi vida" (De Erauso, 2002: 169).

Tanto la vida de la heroína Catalina como sus memorias se relacionan con los estudios de historia, literatura de viajes y escritura de mujeres que reconoce a aquellas féminas del pasado no tan cercano que narraron, viajaron y/o vivieron una vida de desafío y contradicción. Ellas, como Catalina, provocaban a su sociedad para conseguir un objetivo que reconociera su posición y su valor, igual al del soldado o al del conquistador de la época. Algunas escribieron, otras dictaron y de otras escribieron. Esos textos forman parte de una historia diferente y simbólica en los estudios de mujeres españolas, inglesas, francesas, alemanas, africanas, canadienses, peruanas, chilenas, argentinas... Cada origen y cada época histórica particulariza sus 
experiencias pero, en general, todas comparten la lucha por ser reconocidas, por ser consideradas, por tener las mismas oportunidades que el otro género favorito en la sociedad. Se trata de elección. Se trata de libertad. Simple pero en muchos casos, aún imposible. Pasado, presente y futuro siguen unidos en la reivindicación, en la lucha constante por la igualdad de género.

Catalina, La Monja Alférez o Catalina de Erauso como mujer y como ser súper masculino, como monja y como conquistador, se arriesgó y sobrevivió a distintas luchas físicas y psicológicas en un Siglo de Oro para el imperio español. Catalina fue una mujer histórica que viajó entre mundos espaciales y de género. Su carácter "súper masculino" le sirvió para manifestar su autonomía, su independencia y su identidad. Sus hazañas, su viaje y su historia no dejan de ser espectaculares para el lector de ayer, hoy y mañana.

\section{REFERENCIAS}

Aínsa, F. (1986). Identidad cultural de Iberoamérica en su narrativa. Madrid: Gredos.

Bassnett, S. (2002). “Travel Writing and Gender”. En Hulme, P. \& Youngs, T. (Eds.), The Cambridge Companion to Travel Writing (pp. 225-241). Cambridge: Cambridge UP.

Beverley, J. (2004). Testimony: On the Politics of Truth. Minneapolis: University of Minnesota Press.

Blanton, C. (Ed.) (2002). Travel Writing: the Self and the World. New York \& London: Routledge.

Butler, J. (1994). Gender Trouble: Feminism and the Subversion of Identity. New York: Routledge.

De Erauso, C. (2002). Historia de la Monja Alférez, Catalina de Erauso, escrita por ella misma. Ángel Esteban (Ed.). Madrid: Cátedra.

De la Fuente Bastardo, J. L. (2000). "Hispanoamérica: una nueva mujer para un mundo nuevo". En: Moral Padrones, E. y De la Villa Lallana, A. (Eds.), La mujer, alma de la literatura (pp. 191-211). Valladolid: Universidad de Valladolid.

Durán, G. (2004). Catalina, mi padre. México D. F.: Planeta mexicana.

Felski, R. (1989). Beyond Feminist Aesthetics: Feminist Literature and Social Change. Cambridge: Harvard.

Gallardo, J. (2005). Confesiones de la Monja Alférez. La verdadera historia de Catalina de Erauso. Chile: Planeta.

Garber, M. (1993). Vested Interests: Cross-Dressing \& Cultural Anxiety. New York: HarperPerennial.

Hirschfeld, M. (1991). Transvestites: The Erotic Drive to Cross-Dress. New York: Prometheus Books. 
Moureau, F. (2007). "Descubrimientos y redescubrimientos: estado actual de los estudios sobre literatura de viajes”. Oliver, J. M.; Curell, C.; Uriarte, C. G. y Pieco, B. (Eds.), Escrituras y reescrituras del viaje: miradas plurales a través del tiempo y de las culturas (pp. 1-19). Bern: Peter Lang.

Mujica, B. (2004). Women Writers of Early Modern Spain: Sophia's Daughters. New Haven and London: Yale UP.

Myers, K. A. (2002). "Writing of the Frontier: Blurring Gender and Genre in the Monja Alférez's Account”. Arias, S. \& Meléndez, M. (Eds.), Mapping Colonial Spanish America: Places and Commonplaces of Identity, Culture and Experience (pp. 181-202). London: Associated U.P.

Oliver, J. M.; Curell, C.; Uriarte, C. G. y Pieco, B. (Eds.) (2007). Escrituras y reescrituras del viaje: miradas plurales a través del tiempo y de las culturas. Bern: Peter Lang.

Rocha, V. (2003). "El poder del cuerpo y sus gestos. Travestismo e identidad de género en América Colonial: El caso de Catalina de Erauso" Revista Cyber Humanitatis, 27. http://www.cyberhumanitatis.uchile.cl/CDA/texto_simpl e2/0,1255,SCID\%253D7513\%2526ISID\%253D347,00.html

Valenzuela, L. (1993). "The Search, the Writer and the Land of No Evil”. Kenwood, A. (Ed.), Travellers' Tales, Real and Imaginary in the Hispanic World and Its Literature (pp. 3-6). Melbourne \& Madrid: Voz Hispánica.

Vallbona, R. de (1992). Vida i sucesos de la Monja Alférez: autobiografía atribuida a Doña Catalina de Erauso. Tempe: Arizona State University and Center for Latin American Studies.

Wheelwright, J. (1989). Amazons and Military Maids: Women Who Dressed as Men in Pursuit of Life, Liberty and Happiness. London: Pandora Press. 